\title{
A finitude da vida e o papel do psicólogo: perspectivas em cuidados paliativos
}

\section{End of life and psychologist's roles: perspective on palliative care La limitación de la vida y papel del psicólogo: perspectiva de cares paleative}

\author{
Laura Cristina Silva Rezende \\ PUC Minas - Arcos \\ Cristina Sansoni Gomes \\ PUC Minas - Arcos \\ Maria Eugênia da Costa Machadol \\ PUC Minas-Arcos; UNI-BH
}

"Há em cada um de nós um potencial para a bondade que é maior do que imaginamos; para dar sem buscar recompensa; para escutar sem julgar; para amar sem impor condições". KÜBLER-ROSS

\begin{abstract}
Resumo
Os Cuidados Paliativos foram criados para humanizar o atendimento em equipe dos pacientes fora de possibilidades terapêuticas de cura de uma determinada doença. O psicólogo trabalha para facilitar a compreensão do paciente sobre sua atual condição de vida, procurando dar conforto para suas angústias e desta forma amenizar as dores emocionais, respeitando seu tempo diante da aceitação da finitude de sua vida. Este artigo resulta de uma pesquisa bibliográfica acerca das contribuições da assistência psicológica aos pacientes fora de possibilidades terapêuticas de cura, apresentando os princípios que norteiam a modalidade de Cuidados Paliativos e indica, ao final, a relevância do profissional da psicologia neste contexto. Conclui-se que, na perspectiva dos Cuidados Paliativos, o cuidar deve ter prioridade sobre a cura, já que não se pode evitar a morte quando se tem um diagnóstico irreversível de determinadas doenças.

Palavras-chave: Cuidados paliativos; Morte; Psicologia.
\end{abstract}

\begin{abstract}
Palliative Care was created to humanize the team assistance of the patients without therapeutical possibilities of cure of a specific desease. The psychologist works to facilitate patient's understanding about their present life condition, trying to comfort their anguishes and than assuaging emotional pain, by respecting time before the acceptance of life's limitation. This article is based on bibliographical research about the contributions of the psychological assistance to the patients without of therapeutical possibility of cure, presenting the keystones of Palliative Care and points to the importance of a psychology professional in this context. One concludes that, in the perspective of the Palliative Cares, care must be a priority opposing cure, seeing that one can not avoid the death when one has an irreversible diagnosis of a specific sicknesses.
\end{abstract}

Key-words: Palliative care; Death; Psychology.

\begin{abstract}
Resumen
Cuidados Paliativos se crearon para humanizar la atención a los pacientes sin posibilidades terapéuticas de curación de una enfermedad determinada. El Psicólogo trabaja para facilitar la comprensión del paciente sobre su condición actual de vida, en busca de darle comodidad para sus angustias y de esta forma mitigar los dolores emocionales, respetando su tiempo antes de la aceptación de la limitación de su vida. Este artículo es el resultado de una investigación bibliográfica sobre las contribuciones de la asistencia psicológica a los pacientes sin posibilidades terapéuticas de cura, presentando los princípios que orientan la práctica de los cuidados paliativos, señalando, al final, la relevancia profesional de la Psicología en este contexto. Llegase a la conclusión de que, en la perspectiva de los cuidados paliativos, el cuidado deve tener prioridad sobre la cura, ya que no se puede evitar la muerte cuando se tiene un diagnóstico irreversible de determinadas enfermedades.
\end{abstract}

Palabras-clave: Cuidados paliativos; Muerte; Psicología.

\section{INTRODUÇÃO}

Em busca da humanização para o atendimento em equipe de pacientes fora de possibilidade terapêutica

Endereço 1:Rua Júlio Diniz, 219/ 201 Bairro: Santa Branca, Belo Horizonte - Minas Gerais CEP: 31565-180. de cura de uma determinada doença, foi criada a especialidade médica denominada "Cuidados Paliativos". Na área da Psicologia, os Cuidados Paliativos é uma modalidade na qual o psicólogo trabalha para facilitar a compreensão do paciente sobre sua atual condição de vida, procurando dar conforto para suas angústias e desta forma amenizar 
as dores emocionais, respeitando seu tempo diante da aceitação da finitude de sua vida.

Especificamente sobre os profissionais que atuam na área de doenças sem cura, na qual a possibilidade de morte se torna algo muito frequente, percebe-se que os mesmos também precisam de cuidados, porque são preparados para lidar com "a cura" e ao se depararem com uma doença de quadro irreversível, comumente sentem-se impotentes.

Neste sentido, o lidar com a possibilidade de morte está presente cotidianamente no contexto dos Cuidados Paliativos. No entanto, muitas pessoas têm medo de falar e de vivenciar o processo da morte e do morrer, pelo fato de não saberem como é essa experiência. Portanto, tal processo não envolve apenas o paciente, mas também a família e a equipe de saúde, que compartilham desse momento.

Assim, foram investigadas nesse estudo as contribuições da intervenção psicológica aos pacientes, à família e à equipe dos Cuidados Paliativos, sendo que o principal objetivo deste trabalho foi refletir sobre as possíveis contribuições do psicólogo, na perspectiva dos Cuidados Paliativos, com os envolvidos no processo de morte e morrer. Para tanto foi utilizada a pesquisa bibliográfica que, segundo Gil (2002, p. 44) "é desenvolvida com base em material já elaborado, constituído principalmente de livros e artigos científicos". O resultado de tal pesquisa encontra-se apresentado em cinco tópicos, a saber: 1) morte: breve evolução histórica até a perspectiva dos Cuidados Paliativos, 2) fases descritas por Elizabeth Kübler-Ross, 3) o trabalho da equipe de Cuidados Paliativos, 4) comunicação em Cuidados Paliativos e 5) o papel do psicólogo diante do processo de morte e morrer.

Acredita-se que esta pesquisa pode contribuir com a reflexão acerca da importância do psicólogo na equipe dos Cuidados Paliativos, além de possibilitar futuras propostas que visem a humanização nesse contexto.

MORTE: breve evolução histórica até a perspectiva dos Cuidados Paliativos

A morte é um assunto que a maioria das pessoas prefere evitar. Baseando-se em Ribeiro (2008), podese considerar que tal fato se relaciona à dificuldade que o ser humano encontra em lidar com o desconhecido; por isso o pavor e a recusa diante do fato de perder pessoas queridas. Kübler-Ross (1998) acredita que o maior obstáculo a ser enfrentado quando se procura compreender a morte é o fato de que é impossível para as pessoas imaginarem um fim para a sua própria vida.

Quando se recorre à História, percebe-se que o contato com a morte se modificou ao longo do tempo. De acordo com Maranhão (1987), antigamente, a morte era mais próxima da esfera familiar. $\mathrm{O}$ moribundo passava seus últimos momentos em casa, perto das pessoas que amava, tendo direito de realizar os últimos desejos e se redimir de seus erros e desavenças. Já na contemporaneidade boa parte da população nasce e morre nos hospitais, o que torna muitas vezes a morte invisível.

No hospital, o paciente pode vir a ser despido do seu eu, perdendo a dignidade, os direitos de ir e vir, assim como os objetos e eventos que organizam sua vida e dão sentido a sua existência, tais como: o conforto de sua casa, os objetos pessoais, os horários comumente utilizados para alimentação, visitas, higiene, medicamentos dentre outros. Para manter seus órgãos vitais funcionando podem ser introduzidos aparelhos, tubos e agulhas em seu corpo, acompanhados de dores e sofrimento. É por isso que o hospital "possibilita o prolongamento da vida dos doentes pelo maior tempo possível, mas não os ajuda a morrer" (Maranhão, 1987, p. 13).

Segundo Alves (2006) as dores do parto fazem sentido, pois uma vida nova está nascendo. Mas há outras que não existem sentido para o sofrimento devido aos sedativos que podem ser administrados contra as dores e incômodos que acometem os pacientes que estão fora de possibilidade terapêutica de cura (Kübler-Ross, 2005), os quais devem ser acompanhados por uma equipe de Cuidados Paliativos.

Historicamente, a origem dos Cuidados Paliativos ocorreu no movimento hospice. A palavra hospice deriva do latim hospes, que significa estranho; hospitalis que significa amigável, portanto: boas vindas ao estranho. Em 1840, na França, os hospices eram abrigos para que os peregrinos pudessem cuidar de pessoas doentes e feridas durante suas viagens de cunho religioso. Nesses abrigos, cuidavam-se de pessoas enfermas à beira da morte. Esse movimento estendeu-se a outras partes do mundo e em 1967 foi criado em Londres o St Cristopher's Hospice, por Cicely Saunders, que revolucionou a ideia de Cuidados Paliativos e serviu de incentivo para outros grupos na criação de vários hospices independentes (Melo \& Figueiredo, 2006).

Em 1970, nos Estados Unidos, Cicely Saunders e Elizabeth Kübler-Ross se uniram dando continuidade ao crescimento do movimento hospice. Então a partir da evolução do trabalho dessas duas médicas, a Organização Mundial de Saúde [OMS] recomendou em 1982, que todos os países trabalhassem com movimento hospice, visando alívio e cuidados aos pacientes com câncer. Entretanto, o termo hospice foi trocado por Cuidados Paliativos devido às dificuldades de tradução autêntica em alguns idiomas. Em 2002 a OMS recomendou os cuidados paliativos não apenas para os casos de câncer, mas também para todos os pacientes com doenças agressivas ou que indiquem risco à vida (Conselho Regional de Medicina do Estado de São Paulo [CREMESP], 2008). Ou seja, ao 
longo das últimas décadas houve o reconhecimento dos Cuidados Paliativos como cuidados específicos para pacientes que estão sem recurso de tratamento ou cura.

Em 2002, a OMS definiu, pela última vez, os Cuidados Paliativos como:

Uma abordagem que visa melhorar a qualidade de vida dos doentes que enfrentam problemas decorrentes de uma doença incurável com prognóstico limitado, e/ ou doença grave (que ameaça a vida), e suas famílias, através da prevenção e alívio do sofrimento, com recurso à identificação precoce, avaliação adequada e tratamento rigoroso dos problemas físicos, como a dor, mas também psicossociais e espirituais (Academia Nacional de Cuidados Paliativos [ANCP], 2006, p. 2).

Neste sentido, os Cuidados Paliativos são direcionados à melhoria das condições de vida de todos os pacientes com doenças progressivas e irreversíveis, sendo elas doenças crônico-degenerativas, incapacitantes e fatais. É importante ressaltar que os Cuidados Paliativos devem "proporcionar não apenas o alívio, mas a prevenção de um sintoma ou situação de crise" (CREMESP, 2008, p. 17).

Pessini (2006) acrescenta que a dor e o sofrimento precisam de prioridade na hierarquia do cuidado do sistema de saúde, sendo que cuidado significa apoio à condição do outro, e constitui-se numa afirmação do interesse em seu bem estar e do compromisso de fazer o possível para amenizar a situação. Cuidar do outro é dar a ele "tempo", atenção ou algo que possa contribuir para tornar a situação menos penosa e desumana. Portanto, o cuidar deve ter prioridade sobre a cura.

No que se refere à qualidade de vida que os Cuidados Paliativos visa proporcionar ao paciente fora de possibilidade terapêutica de cura, Ribeiro (2008) afirma que:

Quando o objetivo é qualidade de vida, está implícito um juízo de valor ao determinar a futilidade de um determinado tratamento, posto que não há conceito único e universal de qualidade de vida, mas sim um conceito pessoal que varia de pessoa para pessoa. Para tomar decisões baseadas também no conceito de qualidade de vida é necessário considerar os aspectos existenciais do paciente e de sua família (p. 82).

Nessa perspectiva, pode-se dizer que a vivência de uma doença sem cura é singular, apesar de se saber que as pessoas que estão diretamente envolvidas com a notícia de um diagnóstico irreversível passam por algumas fases, as quais foram descritas por KüblerRoss.

\section{FASES DA MORTE E DO MORRER DESCRITAS POR ELIZABETH KÜBLER-ROSS}

O paciente fora de possibilidade terapêutica de cura da doença passa por um processo de finitude chamado "processo de morte e morrer", que foi descrito por Elizabeth Kübler-Ross em cinco estágios, a saber: 1) negação e isolamento; 2) raiva; 3) barganha; 4) depressão e 5) aceitação. Esses estágios podem se alternar, misturar ou serem vividos ao mesmo tempo, sendo que a esperança acompanha todas as fases.

$\mathrm{O}$ primeiro estágio, denominado negação e isolamento, relaciona-se à incapacidade do ser humano de aceitar o fim da própria existência. Kübler-Ross (2005), ao longo de suas pesquisas, percebeu que ao receber o diagnóstico de uma doença irreversível, a reação dos pacientes em geral é: "não, eu não, não pode ser verdade".

Para a autora, a negação é uma defesa temporária que age como um pára-choque após notícias inesperadas, que permite ao paciente se recuperar com o tempo. Por isso, nessa fase, é comum o paciente buscar outros diagnósticos, na esperança de que a primeira conclusão seja um erro (Kübler-Ross, 2002).

Então, o cuidado nesse momento é fazer com que essa negação não se transforme numa negação do tratamento, pois até o paciente morrer estará vivo, e é essa vida que deve ser trabalhada diante da doença e da morte. Nesse estágio o acolhimento da angústia e o suporte emocional são importantes para a continuidade do tratamento (Bifulco, 2006).

Kübler-Ross (2002) afirma ser comum que a negação "passe", na medida em que o paciente percebe que precisa lutar pela vida, dando lugar à aceitação parcial. São raríssimos os casos em que os pacientes negam a doença até o último momento, entretanto isso pode acontecer. Em outros casos pode acontecer do paciente conseguir falar sobre sua situação e de repente esquivar-se do assunto, ficando claro que essa negação pode ir e vir. Em geral, no próximo momento o paciente se desliga da negação e se apropria mais do isolamento.

A raiva é o segundo estágio, no qual o paciente não concorda que esteja passando por essa situação e se pergunta “por que eu?". Quando a negação não consegue mais ser mantida aparece a raiva. Em geral, a raiva é das pessoas que estão à sua volta: dos médicos por não diagnosticarem a tempo da cura, dos familiares, das pessoas que estão sadias, surgindo a revolta e o ressentimento de não ter vivido sua vida de outra forma, dos assuntos inacabados e dos dizeres não falados (Kübler-Ross, 2002).

$\mathrm{O}$ cuidado nessa fase é entender que a raiva não é pessoal e sim uma raiva da situação que não pode ser mudada. É importante não destituir o paciente de sua voz ativa, ou seja, é fundamental fazer com que ele se sinta responsável pelo seu corpo e pelas decisões (Bifulco, 2006). Sobre tais decisões, Castro (2001) salienta que:

Respeitar a autonomia do paciente, portanto, é reconhecer que suas decisões são unicamente suas, mesmo que não de acordo com aquelas tidas como adequadas em uma determinada situação. Reconhecer, ainda, que o direito e a capacidade do paciente de 
decidir por si mesmo está de acordo com seus valores, crenças e principalmente plano de vida (p. 8).

Kübler-Ross (2002) aponta que o paciente, durante o estágio da raiva, se ocupa de sentimentos de raiva, revolta, inveja e ressentimento: "pois é, por que não poderia ter sido ele?” (p. 55). O paciente diante de tal indignação sente raiva de tudo e de todos, descarregando essa raiva nas pessoas próximas, fazendo com que algumas se afastem, sejam elas familiares ou equipe de assistência. Diante de tanta raiva o sentimento retorna para o paciente, alimentando seu comportamento hostil. Por isso, é importante que, tanto a equipe, quanto os familiares, tenham paciência com a raiva do enfermo; ao ouvilo é possível contribuir para melhorar a aceitação do processo de morte, pois o fato de colocar para fora a raiva sem recebê-la de volta, é de grande ajuda. É necessário compreender e não julgar.

No terceiro estágio, chamado de barganha, o paciente tenta adiar a morte fazendo tratos com Deus, com a família e com os médicos, a partir de promessas em ser uma pessoa boa se os dias de sua vida forem prolongados. Como a negação e a raiva não deram certo o paciente acredita que com bons argumentos e mais calma chegará a um acordo para que prolongue a chegada dos últimos momentos. É o estágio menos conhecido e geralmente o que ocorre em um prazo curto. Nesses casos o paciente sempre jura não pedir outro adiamento caso seu pedido seja alcançado (Kübler-Ross, 2002).

A depressão é o quarto estágio, no qual o agravamento da doença se faz presente e a mesma não pode ser negada. A negativa, raiva e barganha dão lugar à depressão, sendo ela uma sensação de perdas iminentes, podendo ser perdas materiais ou emocionais. Logo, o enfermo passa a uma depressão preparatória, proveniente de uma situação real, na qual está prestes a perder tudo e todos que ama. Nesse momento, é importante que o paciente verbalize os seus pesares e remorsos não sendo necessárias frases otimistas ou consoladoras. O silêncio falará mais que as palavras; portanto, é fundamental que o paciente se sinta amparado, tendo conhecimento de que não ficará sozinho nos últimos momentos. Somente aqueles enfermos que superam seus temores e angústias são capazes de chegar ao estágio final, caracterizado pela aceitação (Kübler-Ross, 2002).

Após passar pelos estágios citados anteriormente, $\mathrm{o}$ paciente entra num estágio de tranquilidade no sentido de aceitar sua doença, limitações e possibilidades, quando existem. Kübler-Ross (2002) esclarece que a raiva e a depressão já foram externalizadas através da transmissão de sentimentos e compreensão pelas pessoas que o rodeiam. O enfermo deseja ficar cada vez mais só, sem as perturbações do cotidiano; começa a perder a vontade de conversar. Nesse momento o toque e o silêncio tornam-se a comunicação. "Para o paciente é reconfortante sentir que não foi esquecido quando nada mais pode ser feito por ele" (KüblerRoss, 2002, p. 118).

Neste quinto e último estágio, a aceitação apresenta a necessidade que o paciente tem de se perdoar, de perdoar o outro e ser perdoado. O fim da vida então se aproxima. Segundo Bifulco (2006), ao final desse estágio:

Seu corpo já estará mais fraco e cansado, sentirá uma necessidade maior de dormir. Não se trata de um sono de fuga... Uma preparação. As coisas do mundo não importam mais, assuntos corriqueiros, notícia, barulho, não lhe dizem respeito, há uma introspecção para seu mundo interior. O segurar a mão e o estar próximo dizem mais do que palavras proferidas, o olhar se torna mais parado e distante, como se olhasse sem nada ver. Posteriormente, fica com os olhos cerrados por um tempo mais longo, até que não os abre mais (p. 27).

Há, entretanto pacientes que não alcançam esse estágio, ou seja, não conseguem finalizar o elo com a esperança e lutam até o fim contra a morte; se debatem até não terem mais forças. É importante informar a família e aos profissionais da equipe, para que possam acolher essas manifestações. A família nesse momento precisa de mais cuidados e necessariamente entender o que o paciente precisa, respeitando suas necessidades (Bifulco, 2006).

Sobre a esperança, faz-se importante enfatizar que a mesma faz parte da vivência de todas as etapas do processo de morte e morrer; ela é um sentimento que traz apoio ao paciente durante o tratamento, ajuda na relação de confiança entre paciente e equipe e tem o poder de aliviar dores emocionais. É a força que o paciente tem para lutar e viver ativamente até o fim. Então, quando o paciente não demonstra mais tal expectativa, pode-se pensar no prenúncio de morte iminente, que como já dito anteriormente é um assunto que a maioria das pessoas prefere evitar. Portanto, se faz necessário um acompanhamento especializado, que é denominado de Cuidados Paliativos, tanto para os pacientes quanto para os familiares que recebem um diagnóstico irreversível de cura de uma determinada doença, pois, como também já foi anunciado, o processo de morte e morrer é igualmente vivenciado pela família.

\section{O TRABALHO DA EQUIPE DE CUIDADOS PALIATIVOS}

A organização dos trabalhos de Cuidados Paliativos prestados aos pacientes necessita de uma equipe multidisciplinar, na qual cada um tem sua função especifica e responsabilidades em comum. Os profissionais que compõem a equipe são médicos, enfermeiros, fisioterapeutas e terapeutas ocupacionais para o controle dos sintomas do corpo, os psicólogos, psicoterapeutas, psicanalistas e psiquiatras para os sintomas da mente e por fim sacerdotes das diferentes crenças para o apoio espiritual. Diante 
disso, o "cuidado paliativo é um conjunto de atos multiprofissionais que têm por objetivo efetuar o controle dos sintomas do corpo, da mente, do espírito e do social, que aflige o homem na sua finitude, isto é, quando a morte dele se aproxima" (CREMESP, 2008, p. 55).

Os profissionais que atuam na equipe de Cuidados Paliativos precisam de alguns requisitos como: desenvolver habilidades de escuta ativa, de suporte diante dos limites do adoecimento, de comunicação, conhecimento técnico das situações que irá enfrentar junto ao paciente e sua família e ainda criar estratégias de enfrentamento no que se refere ao fim da vida (CREMESP, 2008).

O psicólogo, como membro da equipe multidisciplinar, trabalha em diversas atividades, tem uma visão ampla no que se refere ao campo da mente, das vivências e expressões do corpo. O psicólogo não focaliza somente o paciente, mas também a família e a própria equipe que acompanha o processo, e como membro participante da equipe ele também necessita de cuidado, pois a convivência com essas situações afetam diretamente suas vidas, gerando sentimentos de frustração, impotência, revolta e fracasso. Se a experiência da morte de outrem for conduzida com esses sentimentos, torna o trabalho desmotivador e sem sentido (CREMESP, 2008).

A equipe que trabalha com o adoecimento, pode se beneficiar das atitudes do profissional da psicologia cujo objetivo é buscar resiliência diante da situação que só piora. É interessante que o psicólogo procure, em conjunto com a equipe multiprofissional, desenvolver atitudes de respeito pela pessoa do paciente numa totalidade, diante dos problemas, desconforto, dor e necessidades nessa busca de autonomia. É importante ainda que a equipe de cuidados paliativos faça visitas semanais ao paciente, a fim de resgatarem dados para uma discussão sobre a sua condição e então proporcionar melhores cuidados em aspectos físicos, emocionais e sociais (CREMESP, 2008). Nesse contexto, a comunicação é fundamental para que $\mathrm{o}$ atendimento efetivo ao paciente e aos familiares aconteça.

\section{COMUNICAÇÃO EM CUIDADOS PALIATIVOS}

A pessoa que sofre deseja ser compreendida, pois além de dores físicas, desenvolve conflitos emocionais e existenciais, para os quais não existem aparelhos ou remédios que possam aliviar. $\mathrm{O}$ paciente precisa sentir-se cuidado e amparado pelos profissionais de saúde. Para que o acolhimento seja efetivo e as necessidades do fim da vida sejam atendidas, os profissionais precisam se apropriar de atitudes como a empatia e a compreensão. Mais que habilidades técnicas e conduta dos profissionais envolvidos no processo, é esperado que a base dessa relação envolva o respeito, a humildade e a compaixão. (Silva \& Araújo, 2009).
É importante compreender que quando se pensa em comunicação nos cuidados paliativos, a qualidade dos relacionamentos se torna mais importante do que a própria doença, já que ela não será "curada"; são os relacionamentos, então, os aspectos mais importantes para qualificar a vida nessa fase. Segundo o CREMESP (2008):

É essencial que os profissionais informem aos pacientes sobre sua doença, para que diante da situação atual, eles possam decidir os próximos passos de sua vida e a relação com seus familiares, lembrando que é direito do paciente saber de sua condição (p. 37).

Para tanto, o profissional de saúde precisa sempre aprimorar seus conhecimentos e habilidades para se comunicar melhor. Precisa saber não apenas a hora e o que falar, mas saber principalmente o momento de ficar em silêncio e ouvir, substituir palavras por olhares e toques afetivos nos braços, mãos ou ombros. A escuta atenta e reflexiva é a maior habilidade a ser desenvolvida (Silva \& Araújo, 2009). Afinal, “o que nos caracteriza como humanos é a capacidade... de ouvir a nós mesmos e aos outros" (Kovács, 2006, p. 86).

O processo de comunicação pode ocorrer em duas dimensões: verbal e não-verbal. A comunicação verbal se aplica em forma de palavras com objetivo de mostrar compreensão ou para expressar pensamentos. $\mathrm{O}$ processo não-verbal diz respeito à entonação e velocidade da voz, assim como ruídos, gestos, olhares, expressões e toques, sendo o último um instrumento utilizado para demonstrar apoio e afeto (Silva \& Araújo, 2009).

Diante, especificamente, da comunicação de notícias difíceis, profissionais e familiares acreditam que falar sobre a situação real pode aumentar o sofrimento do enfermo, por isso optam por não conversar sobre a morte ou a terminalidade; dúvidas e anseios não são compartilhados, criando um isolamento emocional. No entanto, a maior parte dos pacientes com doenças fatais querem saber de sua condição de saúde, porém é necessário respeitar o momento de cada um, identificando o que o paciente sabe e o que ele consegue suportar. Silva e Araújo (2009) ressaltam que é necessário criar habilidades não para decidir se deve ou não contar, mas sim para contar a notícia de uma doença irreversível ou uma piora do quadro clínico.

$\mathrm{Na}$ prática, nas equipes multiprofissionais de Cuidados Paliativos, essas situações são acompanhadas por psicólogos, cuja formação, dentre os demais profissionais, possibilita subsídios para um manejo centrado nas necessidades individuais que exigem as circunstâncias que envolvem as notícias do processo de morte e morrer, as quais se iniciam com a notícia de um diagnóstico irreversível de cura de determinada doença.

O PAPEL DO PSICÓlOGO DIANTE DO 


\section{PROCESSO DE MORTE E MORRER}

O trabalho a ser realizado por psicólogos durante o processo dos Cuidados Paliativos é de suma importância devido à profunda alteração das condições emocionais do paciente e dos participantes desse processo, que são a família e a equipe. $\mathrm{O}$ apoio psicológico é crucial nesse momento para promover uma boa comunicação, aceitação do processo de morte para os envolvidos, assim como proporcionar qualidade de vida para o paciente que sofre com a doença.

Para Ribeiro (2008, p. 109), "a dificuldade do ser humano em geral... em lidar com a morte pode ser trabalhada e melhorada. Com isso, pode haver mais qualidade de vida para todos os envolvidos na questão". Assim o trabalho deve ser dirigido prioritariamente ao paciente em busca de qualidade de vida. Posteriormente, o cuidado se encaminha para a família e para a equipe envolvida, pois, também a morte é para quem fica.

Sabe-se que os pacientes fora de possibilidades de cura de uma determinada doença têm particularidades muito especiais como: sentimentos de impotência e tristeza pela situação adversa em que estão vivendo, entre outros. Tais particularidades poderão ser reconhecidas e atendidas se o psicólogo tiver habilidade e capacidade profissional para escutar e descobrir quais são elas. Por isso, Torres (1999) afirma que "o psicólogo como um profissional que lida essencialmente com relações humanas, tem o compromisso de procurar oferecer condições para que o paciente possa elaborar seu sofrimento através da compreensão, respeito e dignidade" (p. 5).

Para que o trabalho seja eficaz, o profissional da Psicologia deve primeiramente estabelecer um vínculo com o paciente. Além disso, precisa identificar o que o paciente sabe e o que quer saber sobre a doença e sobre sua situação real. O psicólogo ajuda na compreensão da relação entre o paciente e o fato ocorrido, possibilita a percepção dos sentimentos que surgem junto com as dúvidas e incertezas durante o tratamento. Nesse sentido, Torres (1999) salienta que o psicólogo "pode auxiliar o paciente e sua família no conhecimento de possíveis tratamentos..., desmistificando a doença" ( p. 2).

Castro (2001) reflete sobre importância da atuação do psicólogo desde o momento do diagnóstico:

$\mathrm{Na}$ fase de diagnóstico, a atuação do psicólogo pode ajudar a facilitar o ajustamento psicológico do paciente e de sua família quanto na comunicação destes. Ajudando a quebrar o silêncio que pode se instalar, quando às vezes a informação é bloqueada por familiares, os quais consideram que é melhor manter o paciente sem essa informação (p. 5).

Tanto no diagnóstico, quando no tratamento, o paciente vive fortes emoções, sendo importante considerar o tempo de assimilação dos fatos. Trata-se de uma situação delicada, na qual o mesmo procura entender o sentido de sua vida, o sentido do tratamento e de seu sofrimento (Torres, 1999).

O principal papel do psicólogo nesse momento da vida de pacientes fora de possibilidades terapêuticas de cura de uma determinada doença é o apoio, acolhimento e compreensão. Como afirma Maciel (2006) "se o paciente não pode ser curado, podemos auxiliá-lo a ter uma vida com boa qualidade, aliviando seu sofrimento, integrando-o novamente na comunidade e na família" (p. 384).

Para o paciente que está diante de uma doença incurável, às vezes é preciso parar de lutar. Diante do inevitável, o mais corajoso é aceitar. Com a iminência da morte, o melhor a decidir é como viver bem até o fim. Muitos pacientes acreditam que o psicólogo está com eles para convencê-los a aceitar a morte, porém esse profissional está pronto para ouvi-lo e atender a demanda da vida; não está preparado para tratar vida como morte, nem as pessoas como coisas (Brum, 2008). É fundamental lembrar que o paciente está fora de possibilidade de cura, mas o cuidado e atenção, além da autonomia devem ser considerados enquanto o mesmo estiver vivo.

A autonomia nas decisões do paciente repercute diretamente no seu estado físico e emocional, pois lhe dá a oportunidade de exercer a posição de dono de sua própria vida. Ao escutar o paciente, o psicólogo trabalha a fim de compreender o que o mesmo deseja. Castro (2001) acrescenta que: "para que o princípio de autonomia exista na relação paciente/profissional é necessário que o paciente tenha independência de vontade e ação, significando assim que ele tenha o controle de sua capacidade ética" (p. 7).

As intervenções devem valorizar a condição do indivíduo como pessoa humana que pensa e sente, mantendo válidas suas opiniões e decisões. É necessário dar ênfase ao que o paciente carrega de sua história de vida, que está além de sua doença (Torres, 1999). Ao evidenciar o que o paciente traz de sua história o psicólogo contribui para que este perceba o que a vida lhe trouxe, suas conquistas e os bons momentos vividos. A partir daí o processo de aceitação se torna mais viável.

O profissional da Psicologia deve estar sempre preparado para acontecimentos adversos, pois não se pode prever a maneira com que cada pessoa compreende e reage às situações. Segundo Torres (1999, p. 2), "é extremamente importante que o psicólogo compreenda o paciente, sua dor e a sua postura diante de sua doença, sobretudo respeitando-o". É interessante dar oportunidade ao paciente, sempre que for possível e desejoso de sua parte, para falar sobre si mesmo, de sua doença e de sua morte. Isso acontece quando o profissional aceita o paciente como ele é e como ele está, procurando entender e compreender seu medo de morrer sem julgamentos. Morrer e morte são eventos separados e distintos; da morte quase nada se sabe e do morrer 
há muito a se conhecer, principalmente por ser vivido por todos em vida (Muccillo, 2006).

O acolhimento da família por parte do psicólogo é imprescindível, pois ela participa do processo junto ao paciente. A família sente-se acuada diante do desconhecido, se culpa pelo estado do paciente e pela incapacidade técnica de poder ajudá-lo. Assim, o psicólogo deve escutar com atenção a família e sua dor, por saber que a doença do paciente não tem cura, encontrando meios de evidenciar a esperança, o cuidado e a qualidade de vida, além de desmistificar a possibilidade de não ter mais o que fazer (Maciel, 2006).

O trabalho do psicólogo tem por objetivo dar novos significados ao sentido da vida dos pacientes e de suas famílias, sendo um facilitador de comunicação (Maciel, 2006). Nesta direção, o mesmo autor afirma que "por meio do apoio, o paciente pode permitir-se ser cuidado, cuidar de algumas feridas abertas pelo tempo e encontrar formas de falar sobre a morte e finitude, sem sentir-se agredido" (Maciel, 2006, p. 401).

Como a equipe está necessariamente envolvida na evolução da doença do paciente, ela também precisa de cuidados do psicólogo. De acordo com Pauletti, Lunardi Filho, Silva e Lunardi (2006, p. 15) "a interação entre o paciente terminal, sua família e os profissionais de saúde pode ser prejudicada, muitas vezes em decorrência do sofrimento pelo qual passa todos os envolvidos no processo de morrer e morte". Diante disso, o tratamento da equipe se torna mais uma área para o profissional da Psicologia.

Segundo Rodrigues, Zago e Caliri (2005), com o aumento das incidências de doenças crônicodegenerativas, incapacitantes e fatais os profissionais da saúde adoecem cada vez mais por terem que enfrentar situações para as quais não se sentem preparados. Não é usual falar sobre a terminalidade entre os profissionais da saúde. Esses profissionais estão capacitados para lidar com situações de tratamento curativo, e ao se deparem com a impossibilidade de cura, sentem-se impotentes. Diante do convívio com a morte constante existem casos que podem marcar profundamente, como exemplo: quando os profissionais não conseguem realizar o trabalho de aliviar os sintomas e/ou quando são mortes de pacientes jovens ou ainda de pacientes que criaram vínculo com a equipe. Diante dessa condição fica clara a importância do trabalho da Psicologia com os profissionais que, têm em seu cotidiano, pacientes gravemente enfermos em tratamento, envolvendo situações de estresse prolongado, convivendo com dor, sofrimento e impotência (CREMESP, 2008).

Para que os profissionais, inclusive o psicólogo da equipe de cuidados paliativos, lidem com situações de morte de forma mais adequada, é importante que também tenham apoio psicológico. Através da escuta, esses profissionais encontraram espaço para expressarem seus sentimentos e emoções, resultando na amenização do sofrimento e consequentemente melhores condições para realizar o trabalho com o paciente.

\section{CONSIDERAÇÕES FINAIS}

A partir da discussão da literatura científica relacionada aos Cuidados Paliativos, pode-se concluir que é importante a inserção da Psicologia na equipe que oferece tais cuidados, tendo em vista que a mesma, por muitas vezes, apresenta um grande sofrimento psíquico e existencial.

O trabalho do psicólogo é imprescindível, pois ao mesmo tempo em que busca aliviar o sofrimento emocional de todos os envolvidos no processo, trabalha com o paciente em prol de qualidade de vida e melhor aceitação da morte. A família do paciente vivencia junto dele todo o processo e ao ver a pessoa querida diante da morte sente-se impotente para ajudá-la, tendo consciência que após o óbito é ela quem continuará viva.

O psicólogo intervém para melhorar a comunicação, para que o paciente e a família resolvam os seus conflitos e a partir daí sintam-se mais confortados, além de contribuir para a elaboração acerca das questões relacionadas ao luto.

A equipe também se envolve nesse processo, pois além de conviver diariamente com situações de morte, pode se apegar a determinados pacientes. O psicólogo, nesse momento, deve proporcionar um espaço de escuta, por meio dos atendimentos individuais ou em grupos, com a pretensão de amenizar os sentimentos e emoções causados pelo fato de ter que lidar com a possibilidade da morte cotidianamente.

É interessante que esse psicólogo também seja ouvido, porém por um psicólogo que não seja membro da equipe, para que os sentimentos envolvidos na situação de cuidar de pessoas com doenças ameaçadoras da vida não interfiram no cuidado que ele oferece a outrem. Portanto, pode-se dizer que todos os profissionais envolvidos precisam de capacitação para lidar com as situações que envolvem os Cuidados Paliativos.

A partir deste estudo pode-se refletir sobre propostas que visem a humanização da área da saúde, para que os profissionais possam lidar melhor com a impossibilidade de cura e buscar possíveis mudanças em relação à comunicação do diagnóstico e acompanhamento. É interessante pensar na possibilidade de incluir na grade da formação dos psicólogos e de profissionais da saúde, disciplinas que abordem especificamente os Cuidados Paliativos, no sentido de acompanhar a demanda que cresce cada vez mais e contribuir para que esses profissionais saiam da graduação preparados para enfrentar as doenças ameaçadoras da vida e a imprevisibilidade da morte. 


\section{REFERÊNCIAS}

ANCP. Academia Nacional de Cuidados Paliativos (2006). Organização de serviços de cuidados paliativos: recomendações da ANCP. Rio de Janeiro: Diagraphic.

Alves, R. (2006). Sobre a morte e o morrer. In: M. T. A. Figueiredo (Org.), Coletânea de textos sobre cuidados paliativos e tanatologia. São Paulo: Unifesp.

Bifulco, V. A. (2006). Psicologia da morte. M. T. A. Figueiredo (Org.), Coletânea de textos sobre cuidados paliativos e tanatologia (p. 24-27). São Paulo: Unifesp.

Brum, E. (2008). A enfermaria entre a vida e a morte. Revista Época - Saúde e bem estar. Recuperado em 16 de setembro de 2010, de http://revistaepoca.globo.com/Revista/Epoca/0, ERT1039915257-10399-3934,00.html.

Castro, D. A. (2001). Psicologia e Ética em Cuidados Paliativos. Brasília: Psicologia ciência e profissão, 21(4), 44-51.

CREMESP. Conselho Regional de Medicina do Estado de Minas Gerais (2008). Cuidado paliativo. Coordenação Institucional de Reinaldo Ayer de Oliveira. São Paulo: Cremesp.

Gil, Antônio Carlos. Como elaborar projetos de pesquisa. 4. Ed. São Paulo: Atlas, 2002.

Kovács, M. J. (2006). Comunicação em cuidados paliativos. In: C. A. M. Pimenta; D. D. C. F.

Mota; D. A. L. M. Cruz (Org.), Dor e cuidados paliativos: enfermagem, medicina e psicologia (p. 86-102). Barueri: Manole.

Kübler-Ross, E. (1998). A roda da vida: memórias do viver e do morrer. Rio de Janeiro:Sextante.

Kübler-Ross, E. (2002). Sobre a morte e o morrer: o que os doentes terminais têm para ensinar a médicos, enfermeiras, religiosos e aos seus próprios parentes. São Paulo: Martins Fontes.

Kübler-Ross, E. (2005). Sobre a morte e o morrer: o que os doentes terminais têm para ensinar a médicos, enfermeiras, religiosos e aos seus próprios parentes. São Paulo: Martins Fontes.

Maciel; M. G. S. (2006). Modelo de intervenção em cuidados paliativos: a experiência do HSPE-SP. In: C. A. M. Pimenta; D. D. C. F. Mota; D. A. L. M. Cruz (Org.), Dor e cuidados paliativos: enfermagem, medicina e psicologia (p. 384-408). Barueri: Manole.

Maranhão, J. L. S. (1987). O que é morte. São Paulo: Brasiliense.

Melo, A. G. C.; Figueiredo, M. T. A. (2006). Conceitos básicos, histórico e realizações da Associação Brasileira de Cuidados Paliativos e da Associação Internacional de Hospice e Cuidados Paliativos. In: C. A. M. Pimenta; D. D. C. F. Mota; D. A. L. M.

Cruz (Org.), Dor e cuidados paliativos: enfermagem, medicina e psicologia (p. 16- 28). Barueri: Manole.

Muccillo, N. (2006). O preparo do corpo após a morte: aspectos culturais, cuidados físicos e emocionais. In: C. A. M. Pimenta; D. D. C. F. Mota; D. A. L. M. Cruz (Org.), Dor e cuidados paliativos: enfermagem, medicina e psicologia (p. 347-359). Barueri: Manole.

Pauletti, G; Lunardi Filho, W. D; Silva, M. R. S. da; Lunardi, V. L. (2006) Percepções/posturas da equipe multiprofissional de saúde sobre a participação da família nas tomadas de decisão na assistência ao paciente terminal.Rio de Janeiro: Enfermagem Brasil: revista científica dos profissionais de enfermagem, 5(1), 12-19.

Pessini, L. (2006). Bioética e cuidados paliativos: alguns desafios do cotidiano aos grandes dilemas. In: C. A. M. Pimenta; D. D. C. F. Mota; D. A. L. M. Cruz (Org.), Dor e cuidados paliativos: enfermagem, medicina e psicologia (p. 45-66). Barueri: Manole.

Ribeiro, E. E. (2008). Tanatologia: vida e finitude. Rio de Janeiro: Unati.

Rodrigues, I. G.; Zago, M. M. F.; Caliri, M. H. (2005) Uma análise do conceito de cuidados paliativos no Brasil: artigo de revisão. São Paulo: Mundo da saúde, 29(2), 147-154.

Silva, M. J. P.; Araújo, M. M. T. (2009). Comunicação em cuidados paliativos. In: Academia

Nacional de Cuidados Paliativos. Manual de cuidados paliativos. Rio de Janeiro: Diagraphic.

Torres, T. L. (1999). O psicólogo centrado na pessoa e a instituição hospitalar. In: FÓRUM BRASILEIRO DA A.C.P. Ouro
Preto. Recuperado em 25 de março de 2010, de http://www.apacp. org.br/art055.html.
Recebido: 30/08/2012

Última revisão: 29/04/2014

Aceite final: 05/05/2014 
Sobre os autores:

Laura Cristina Silva Rezende - Especialista em Psicologia Hospitalar

Cristina Sansoni Gomes - Especialista em Psicologia Humanista-Existencial

Maria Eugênia da Costa Machado - Mestre em Saúde da Mulher.

E-mail: mcostamachado@yahoo.com.br 